\title{
EL OFTALMÓLOGO CONSUMISTA
}

\section{THE CONSUMIST OPHTHALMOLOGIST}

\author{
DURÁN-DE-LA-COLINA JA ${ }^{1}$
}

El empleo de la tecnología, al igual que en la dinámica de la sociedad, ha ejercido una influencia determinante en la evolución de la oftalmología de los últimos años. El efecto de los nuevos instrumentos no solamente ha permitido reconocer y tratar mejor las enfermedades oculares, sino que ha impulsado cambios en la estrategia profesional y ha colocado a la especialidad en un alto nivel de prestigio social.

El debate sobre el lugar que corresponde a la tecnología en la medicina se remonta a siglos atrás, cuando el estetoscopio o el oftalmoscopio se interpusieron por primera vez entre el médico y el paciente. Somos testigos del crecimiento de la oftalmología en las últimas décadas de la mano de la facoemulsificación, la vitrectomía, la angiografía y los láseres, por citar los más reconocidos. No han existido dudas de que su empleo aportaba a la práctica clínica un progreso del que se beneficiaba, sobre todo, el paciente. Su adquisición dependía exclusivamente de las posibilidades económicas y de la decisión médica para asumir el cambio. Pero eso solamente fue al comienzo. Intuyendo el futuro, nuestro compañero Pedro Bosch supo ver, ya hace años, la invasión de nuevos instrumentos y su influencia en la práctica de la profesión. Así, con gran ingenio, propuso «un tratado de no proliferación de nuevos instrumentos en oftalmología». Lógicamente, no se le tuvo muy en cuenta.

¿Y en dónde nos encontramos ahora? La proliferación ha ocurrido y eso ha ocasionado que muchos oftalmólogos se encuentren ciertamente perplejos. Ante el nutrido escaparate y con las mercancías elaboradas, observamos cremas antiaberraciones, lociones acomodativas, pócimas para los ataques de histéresis, y otros muchos productos que atiborran las estanterías. Los congresos se convierten en amplios «malls» en donde la mercancía exhibida se convierte en objeto de deseo. Este exceso de oferta genera en el oftalmólogo una ansiedad en la que intervienen, por igual, la razón y la codicia. Desde un punto de vista racional y dando por supuesto el interés de su aplicación, la adquisición de un nuevo instrumento deberá contar con el espacio para su ubicación, el tiempo que requiere su empleo y el análisis de los resultados, sin contar consumibles, horas de aprendizaje y mantenimiento. No es excepcional que el rendimiento de algunos instrumentos haya quedado reducido a una presentación atractiva, algún artículo o, en el mejor de los casos, una tesis doctoral. Todo ello sin desdeñar su misión en el «escaparate» de una clínica.

Pero, tras la perturbación previa de la compra, en el homo eligens el cumplimiento del deseo se acompaña de una gratificación muy alejada del ámbito racional. En la apoteosis de lo nuevo, la «EyeStation 3 » sustituirá a la 2, antes de finalizar el leasing. Disponer del nuevo «I-Las» elevará el ranking profesional varios escalones, eso sí, por un tiempo limitado.

Los miembros de una sociedad siempre han necesitado autoridades que les ayuden a discernir y a tomar decisiones, más cuando se vive en escenarios de creciente complejidad. En la medicina en general y en la oftalmología en particular, se han ido «fabricando» líderes de opinión que contribuyen a dirigir la voluntad de los médicos perplejos e indecisos ante la inabarcable oferta. El primero que adquiere la nueva «WII-sight» será elevado automáticamente a esa categoría de élite. Nadie dirá jamás en público que lo que ha adquirido es inútil o ruinoso. Incluso ocurre que el alto precio de algunas tecnologías obliga a buscar nuevas aplicaciones para poder así justificar la inversión. Instrumentos en busca de patologías.

¿Quién paga, en último término, el oftalmoconsumismo? Está claro que, cuando se trata de medi-

\footnotetext{
${ }^{1}$ Doctor en Medicina. Catedrático de Oftalmología. Instituto Clínico-Quirúrgico de Oftalmología. Universidad del País Vasco. Bilbao. España. E-mail: duran@icqo.org
} 
cina privada, lo hace el paciente o el mismo médico. Acerca de la racionalidad en la compra de nuevas tecnologías en la sanidad pública sería necesario un debate largo, complejo y delicado.

Debemos reconocer que la tecnología ha configurado decisivamente lo que somos profesionalmente, que no estaríamos en donde estamos sin ella. Que numerosas empresas han contribuido decisivamente al bienestar de la sociedad. Pero la presión y el consumismo tecnológicos pueden desplazar y ocultar algunas de las prioridades de la medicina.
Es ingenuo aceptar todo lo publicado en las revistas, de impacto o de tabloide, de donde nacen las corrientes científicamente o comercialmente correctas. Las opiniones no coincidentes con las leyes del consumo son a menudo desaprobadas o ninguneadas. De acuerdo con las preocupaciones sociales del momento, hace años se proponía una «no proliferación de nuevos instrumentos». Yo propongo actualmente un «crecimiento sostenible y renovable de la oftalmología». Todo depende de nosotros. 